\title{
Addressing the Potential Role of Fingolimod in Cancer Therapy
}

\section{Carratù Maria Rosaria*}

Department of Biomedical Sciences and Human Oncology, Aldo Moro University of Bari, Medical School, Policlinico Piazza Giulio Cesare 11, 70124 Bari, Italy

\begin{abstract}
Fingolimod is a well known immunomodulator used by oral route in relapsing multiple sclerosis patients. Upon phosphorylation by sphingosine kinase 2 (SPHK2), fingolimod binds to one or more of at least five G protein coupled receptors known as S1PR1-5, thus it causes S1PRs internalization and consequent sequestration of lymphocytes in lymphoid organs. Fingolimod also affects other signaling pathways. In particular, this drug is able to activate the serine-threonine protein phosphatase 2A (PP2A) which regulates multiple cell signaling cascades by virtue of its phosphatase activity. PP2A loss-of-function may represent one of the major events contributing to cancer development and progression. Hence, there is a need for therapeutic PP2A reactivation. In this regard, fingolimod is revealing a promising candidate for cancer treatment due to its ability to reactivate PP2A, reduce cell viability and promote apoptosis. However, the appropriate dosage and safety remain a challenge.
\end{abstract}

\section{Keywords: Fingolimod; PP2A; Cytotoxicity; Apoptosis; Cancer}

\section{Introduction}

Fingolimod (FTY720), a myriocin analogue structurally related to sphingosine, is a well known immunomodulator, currently used by oral route in relapsing multiple sclerosis patients [1,2]. Upon phosphorylation by sphingosine kinase 2 (SPHK2), fingolimod binds to one or more of at least five $G$ protein coupled receptors known as S1PR1-5. S1PR1 couples to Gi to activate Ras/ERK and PI3-kinase/ Akt pathways leading to mitogenic and survival signaling as well as cell migration [3]. S1PR2 couples with multiple heterotrimeric G proteins, including G12/13 which exerts a potent inhibitory effect on Rac GTPase with consequent inhibition of cell migration [3]. Although fingolimod has an initial agonist activity at S1PRs, it subsequently causes internalization and consequent reduction of receptor levels on the cell surface, thus interfering with immune cell trafficking between lymphoid organs and peripheral blood [4-6].

Although fingolimod exerts the immunosuppressive effects by modulating S1PRs signaling, thus leading to sequestration of lymphocytes in lymphoid organs, it also affects other signaling pathways. These non classical effects have been referred to as "off-target" since they are induced when fingolimod is used at concentrations higher than those required for its classical "on-target" action as a S1PR ligand [7]. As a sphingosine analogue, fingolimod influences other components of the sphingolipids pathway. In particular, it inhibits and reduces the expression of SPHK1 [8,9] and SPHK2 [10], is a competitive inhibitor of ceramide synthase [11,12] and an inhibitor of S1P lyase [13]. Of note, fingolimod is also able to activate the serine-threonine protein phosphatase 2A (PP2A) which regulates multiple cell signaling cascades by virtue of its phosphatase activity. For instance, PP2A counteracts most of the signals triggered by protein kinases, hence controls apoptotic pathways, translation of oncogenic proteins, and cell division [14]. PP2A loss-of-function may represent one of the major events contributing to cancer development and progression. Alterations of the regulatory and scaffold subunits as well as dysregulation of other binding partners of PP2A have been found in numerous malignancies [14,15]. Hence, there is a need for its therapeutic reactivation.

\section{Is fingolimod tailored for cancer therapy?}

The ability of fingolimod to activate PP2A seems to be independent from SPHK2 phosphorylation and S1PR1 interaction [16]. Fingolimodinduced activation of PP2A seems to be due to a direct effect on the PP2A heterotrimeric complexes with consequent Akt dephosphorylation independently from PI3-kinase inhibition [17]. However, fingolimod is able to inactivate the PI3K/Akt via inhibition of PI3K [18] or increase in the expression of PTEN (phosphatase and tensin homologue) which regulates PI3K activity [19]. Of note, the PI3K/Akt pathway could also be activated by S1P [7]. Therefore fingolimod could inhibit the PI3K/ Akt pathway via S1P-dependent and -independent mechanisms.

Loss of PP2A function can be achieved through the aberrant expression of regulatory factors interacting with PP2A. Among them, CIP2A (cancerous inhibitor of PP2A) interacts with PP2A, thus inhibiting PP2A-dependent dephosphorylation of oncogenes such as c-Myc [20]. SET (I2PP2A, inhibitor 2 of PP2A) is an additional binding partner of PP2A with specific inhibitory activity [21]. Fingolimod interacts with SET/PP2A complexes and also reduces the expression of SET, thus leading to PP2A reactivation [22]. However, the mechanism underlying the anticancer property of fingolimod is more complex than one could expect on the basis of simple PP2A reactivation because of the extensive crosstalk among signaling pathways which participate in the regulation of cell metabolism, proliferation and survival.

Fingolimod is cytotoxic and reduces efficiently the viability of cancer cell lines in vitro with apparently minimal effects on normal cells [7]. The majority of studies have shown that cytotoxicity of fingolimod depends on the ability to promote apoptosis via activation of both extrinsic and intrinsic pathways [23-26] or even induce autophagy [27]. Apoptosis induced by fingolimod in several haematological cancer cells appears to be mediated by PP2A activation and consequent downstream dephosphorylation of ERK1/2. In fact okadaic acid, a selective PP2A inhibitor with tumor-promoting activity, is able to rescue these cells from fingolimod-induced death [28]. One of the most challenging aspect of the pharmacological profile of fingolimod is the ability to kill some cancer cells resistant to conventional chemotherapy [16,23,29-31] and sensitize cancer cells to radiation [9,32,33]. At cytotoxic concentrations, fingolimod induces $G_{1}$ phase cell cycle arrest by either down-regulating cyclin D1, cyclin $\mathrm{E}$ and cyclin-dependent

*Corresponding author: Carratù Maria Rosaria, Department of Biomedica Sciences and Human Oncology, Aldo Moro University of Bari, Policlinico, Piazza Giulio Cesare 11, 70124 Bari, Italy, Tel: +390805478455; Fax: +390805478444; E-mail: mariarosaria.carratu@uniba.it

Received February 26, 2016; Accepted March 11, 2016; Published March 14 2016

Citation: Carratù MR (2016) Addressing the Potential Role of Fingolimod in Cance Therapy. Med chem (Los Angeles) 6: 195-197. doi:10.4172/2161-0444.1000345

Copyright: () 2016 Rosaria CM. This is an open-access article distributed under the terms of the Creative Commons Attribution License, which permits unrestricted use, distribution, and reproduction in any medium, provided the original author and source are credited. 
kinases (CDK)2/4 or up-regulating the CDK inhibitors [18,19,26,34,35]. Fingolimod-induced cell cycle arrest and inhibition of cell proliferation appear to be mediated by both PP2A $[29,36]$ and PTEN/PI3K/Akt signaling pathways $[18,19]$. Moreover, there is evidence that FTY720 is phosphorylated by SPHK2 in breast cancer cells and accumulates in the nucleus [37]. Nuclear FTY720-P is a potent inhibitor of class I histone deacetylases (HDACs) that enhance histone acetylation and regulate the expression of a restricted set of genes independently of its known effects on canonical signaling through S1PR1 [37]. In ERa-negative human and murine breast cancer cells, FTY720 reactivates expression of silenced ERa receptors and sensitizes them to tamoxifen [37]. These effects underline the potential benefit of fingolimod in the management of breast cancer resistant to conventional hormonal therapy.

Interestingly, at concentrations lower than those causing cytotoxicity, fingolimod exhibits anti-migratory and/or anti-invasive effects in different cancer cell lines in agreement with its ability to induce cytoskeletal disorganization [38]. Moreover, fingolimod suppresses lymph node and organ metastasis in in vivo cancer models [7]. The SPHK1/S1P/S1PR signaling pathway appears to play a key role in mediating the effects of fingolimod on migration/invasion and metastasis [30,39]. Notably, fingolimod is able to down-regulate the active form of small GTPases, such as RhoA and Rac, which are downstream effectors of the S1PRs and key regulators of cell mobility $[37,40,41]$. These properties make fingolimod a potential drug tailored for the management of late stage disease. Moreover, fingolimod has been shown to inhibit angiogenesis at low doses. In particular, it is able to revert the effects of S1P on the migration of human umbilical vein endothelial cells (HUVEC) and vascular smooth muscle cells (VSMC), and down-regulate VEGF [42-45].

\section{Conclusions}

The ability of fingolimod to target multiple signaling pathways suggests that this drug could be useful to fight against a wide range of malignancies with a larger benefit for late stage and/or chemotherapy-resistant disease. However, the toxicity profile of fingolimod deserves much attention. The main side effects reported in MS patients treated with higher doses of fingolimod can be ascribed to immunosuppression [46,47]. However, transient bradycardia, reversible cerebral vasoconstriction syndrome, acute lymphoblastic leukemia, lymphomatoid papulosis, melanoma, macular edema and retinal hemorrhage have been also reported [48-54]. On the other hand, it is difficult to actually predict the toxicity profile in cancer patients as the treatment schedule may differ substantially from that used in MS patients. In vitro studies indicate that the anticancer effect may be achieved using a dose range higher than that necessary to antagonize S1PR signaling. Since there are side effects associated with inhibition of S1P signaling, fingolimod derivatives lacking S1P signaling capability but retaining the cytotoxic property or derivatives with enhanced sphingosine kinase inhibition are arousing strong interest to pharmaceutical and biotechnology companies [7]. Moreover, single or dual antibody liposomal formulations for targeted delivery of fingolimod could represent a further strategy to reduce unwanted toxicity [7]. However, accurate evaluation of actual benefits of fingolimod and its derivatives in different cancer settings as well as clinical trials are needed before claiming this drug as a potential candidate for inclusion in the repertoire of anticancer therapy.

\section{References}

1. Cohen JA, Barkhof F, Comi G, Hartung HP, Khatri BO, et al. (2010) Oral fingolimod or intramuscular interferon for relapsing multiple sclerosis. $\mathrm{N}$ Engl J Med 362: 402-415.

2. Derfuss T, Bergvall NK, Sfikas N, Tomic DL (2015) Efficacy of fingolimod in patients with highly active relapsing-remitting multiple sclerosis. Curr Med Res Opin 31: 1687-1691.

3. Adada M, Canals D, Hannun YA, Obeid LM (2013) Sphingosine-1-phosphate receptor 2. FEBS J 280: 6354-6366.

4. Mehling M, Johnson TA, Antel J, Kappos L, Bar-Or A (2011) Clinical immunology of the sphingosine 1-phosphate receptor modulator fingolimod (FTY720) in multiple sclerosis. Neurology 76: S20-S27.

5. Ingwersen J, Aktas O, Kuery P, Kieseier B, Boyko A, et al. (2012) Fingolimod in multiple sclerosis: mechanisms of action and clinical efficacy. Clin Immunol 142: $15-24$.

6. Chiba K, Matsuyuki H, Maeda Y, Sugahara K (2006) Role of sphingosine 1-phosphate receptor type 1 in lymphocyte egress from secondary lymphoid tissues and thymus. Cell Mol Immunol 3: 11-19.

7. Patmanathan SN, Yap LF, Murray PG, Paterson IC (2015) The antineoplastic properties of FTY720: evidence for the repurposing of fingolimod. J Cell Mol Med 19: 2329-2340.

8. Tonelli F, Lim KG, Loveridge C, Long J, Pitson SM, et al. (2010) FTY720 and (S)-FTY720 vinylphosphonate inhibit sphingosine kinase 1 and promote its proteasomal degradation in human pulmonary artery smooth muscle, breast cancer and androgen-independent prostate cancer cells. Cell Signal 22: 15361542.

9. Pchejetski D, Bohler T, Brizuela L, Sauer L, Doumerc N, et al. (2010) FTY720 (fingolimod) sensitizes prostate cancer cells to radiotherapy by inhibition of sphingosine kinase-1. Cancer Res 70: 8651-8661.

10. Li MH, Hla T, Ferrer F (2013) FTY720 inhibits tumor growth and enhances the tumor-suppressive effect of topotecan in neuroblastoma by interfering with the sphingolipid signaling pathway. Pediatr Blood Cancer 60: 1418-1423.

11. Kim HJ, Qiao Q, Toop HD, Morris JC, Don AS (2012) A fluorescent assay for ceramide synthase activity. J Lipid Res 53: 1701-1707.

12. Lahiri S, Park H, Laviad EL, Lu X, Bittman R, et al. (2009) Ceramide synthesis is modulated by the sphingosine analog FTY720 via a mixture of uncompetitive and noncompetitive inhibition in an Acyl-CoA chain length-dependent manner. J Biol Chem 284: 16090-16098.

13. Bandhuvula P, Tam YY, Oskouian B, Saba JD (2005) The immune modulator FTY720 inhibits sphingosine-1-phosphate lyase activity. J Biol Chem 280: 33697-33700.

14. Ciccone M, Calin GA, Perrotti D (2015) From the Biology of PP2A to the PADs for Therapy of Hematologic Malignancies. Front Oncol 5: 21.

15. Sangodkar J, Farrington C, McClinch K, Galsky MD, Kastrinsky DB, et al. (2015) All roads lead to PP2A: Exploiting the therapeutic potential of this phosphatase. FEBS J.

16. Neviani P, Santhanam R, Oaks JJ, Eiring AM, Notari M, et al. (2007) FTY720, a new alternative for treating blast crisis chronic myelogenous leukemia and Philadelphia chromosome-positive acute lymphocytic leukemia. J Clin Invest 117: 2408-2421.

17. Matsuoka Y, Nagahara Y, Ikekita M, Shinomiya T (2003) A novel immunosuppressive agent FTY720 induced Akt dephosphorylation in leukemia cells. Br J Pharmacol 138: 1303-1312.

18. Lee TK, Man K, Ho JW, Sun CK, Ng KT, et al. (2004) FTY720 induces apoptosis of human hepatoma cell lines through PI3-K-mediated Akt dephosphorylation. Carcinogenesis 25: 2397-2405.

19. Zheng T, Meng X, Wang J, Chen X, Yin D, et al. (2010) PTEN- and p53 mediated apoptosis and cell cycle arrest by FTY720 in gastric cancer cells and nude mice. J Cell Biochem 111: 218-228.

20. Junttila MR, Puustinen $P$, Niemela M, Ahola R, Arnold H, et al. (2007) CIP2A inhibits PP2A in human malignancies. Cell 130: 51-62.

21. Li M, Makkinje A, Damuni Z (1996) The myeloid leukemia-associated protein SET is a potent inhibitor of protein phosphatase 2A. J Biol Chem 271: 1105911062.

22. Pippa R, Dominguez A, Christensen DJ, Moreno-Miralles I, Blanco-Prieto MJ, et al. (2014) Effect of FTY720 on the SET-PP2A complex in acute myeloid leukemia; SET binding drugs have antagonistic activity. Leukemia 28: 19151918.

23. Kiyota M, Kuroda J, Yamamoto-Sugitani M, Shimura $Y$, Nakayama R, et al (2013) FTY720 induces apoptosis of chronic myelogenous leukemia cells via 
dual activation of BIM and BID and overcomes various types of resistance to tyrosine kinase inhibitors. Apoptosis 18: 1437-1446.

24. Yasui H, Hideshima T, Raje N, Roccaro AM, Shiraishi N, et al. (2005) FTY720 induces apoptosis in multiple myeloma cells and overcomes drug resistance. Cancer Res 65: 7478-7484.

25. Lee YS, Nakajima H, Tsuruga M, Magae J (2003) Elimination of cellcycle regulators during caspase-3-dependent apoptosis caused by an immunosuppressant, FTY720. Biosci Biotechnol Biochem 67: 467-474.

26. Permpongkosol S, Wang JD, Takahara S, Matsumiya K, Nonomura N, et al (2002) Anticarcinogenic effect of FTY720 in human prostate carcinoma DU145 cells: modulation of mitogenic signaling, FAK, cell-cycle entry and apoptosis. Int J Cancer 98: 167-172.

27. Liao A, Hu R, Zhao Q, Li J, Li Y, et al. (2012) Autophagy induced by FTY720 promotes apoptosis in U266 cells. Eur J Pharm Sci 45: 600-605.

28. Liu Q, Zhao X, Frissora F, Ma Y, Santhanam R, et al. (2008) FTY720 demonstrates promising preclinical activity for chronic lymphocytic leukemia and lymphoblastic leukemia/lymphoma. Blood 111: 275-284.

29. Roberts KG, Smith AM, McDougall F, Carpenter H, Horan M, et al. (2010) Essential requirement for PP2A inhibition by the oncogenic receptor c-KIT suggests PP2A reactivation as a strategy to treat c-KIT+ cancers. Cancer Res 70: $5438-5447$

30. Lee JW, Ryu JY, Yoon G, Jeon HK, Cho YJ, et al. (2015) Sphingosine kinase 1 as a potential therapeutic target in epithelial ovarian cancer. Int $\mathrm{J}$ Cancer 137 : 221-229.

31. Zhang N, Qi Y, Wadham C, Wang L, Warren A, et al. (2010) FTY720 induces necrotic cell death and autophagy in ovarian cancer cells: a protective role of autophagy. Autophagy 6: 1157-1167.

32. Marvaso G, Barone A, Amodio N, Raimondi L, Agosti V, et al. (2014) Sphingosine analog fingolimod (FTY720) increases radiation sensitivity of human breast cancer cells in vitro. Cancer Biol Ther 15: 797-805.

33. Huang X, Taeb S, Jahangiri S, Emmenegger U, Tran E, et al. (2013) miRNA-95 mediates radioresistance in tumors by targeting the sphingolipid phosphatase SGPP1. Cancer Res 73: 6972-6986.

34. Liu Q, Alinari L, Chen CS, Yan F, Dalton JT, et al. (2010) FTY720 shows promising in vitro and in vivo preclinical activity by downmodulating Cyclin D1 and phospho-Akt in mantle cell lymphoma. Clin Cancer Res 16: 3182-3192.

35. Lu Z, Wang J, Zheng T, Liang Y, Yin D, et al. (2014) FTY720 inhibits proliferation and epithelial-mesenchymal transition in cholangiocarcinoma by inactivating STAT3 signaling. BMC Cancer 14: 783.

36. Saddoughi SA, Gencer S, Peterson YK, Ward KE, Mukhopadhyay A, et al (2013) Sphingosine analogue drug FTY720 targets I2PP2A/SET and mediates lung tumour suppression via activation of PP2A-RIPK1-dependent necroptosis. EMBO Mol Med 5: 105-121.

37. Hait NC, Avni D, Yamada A, Nagahashi M, Aoyagi T, et al. (2015) The phosphorylated prodrug FTY720 is a histone deacetylase inhibitor that reactivates ERa expression and enhances hormonal therapy for breast cancer. Oncogenesis 4: e156.

38. Zhou C, Ling MT, Kin-Wah Lee T, Man K, Wang X, et al. (2006) FTY720, a

Citation: Carratù MR (2016) Addressing the Potential Role of Fingolimod in Cancer Therapy. Med chem (Los Angeles) 6: 195-197. doi:10.4172/2161 0444.1000345 fungus metabolite, inhibits invasion ability of androgen-independent prostate cancer cells through inactivation of RhoA-GTPase. Cancer Lett 233: 36-47.

39. Kluk MJ, Ryan KP, Wang B, Zhang G, Rodig SJ, et al. (2013) Sphingosine1-phosphate receptor 1 in classical Hodgkin lymphoma: assessment of expression and role in cell migration. Lab Invest 93: 462-471.

40. Murali A, Rajalingam K (2014) Small Rho GTPases in the control of cell shape and mobility. Cell Mol Life Sci 71: 1703-1721.

41. Lee TK, Man K, Ho JW, Wang XH, Poon RT, et al. (2005) Significance of the Rac signaling pathway in HCC cell motility: implications for a new therapeutic target. Carcinogenesis 26: 681-687.

42. Ho JW, Man K, Sun CK, Lee TK, Poon RT, et al. (2005) Effects of a nove immunomodulating agent, FTY720, on tumor growth and angiogenesis in hepatocellular carcinoma. Mol Cancer Ther 4: 1430-1438.

43. LaMontagne K, Littlewood-Evans A, Schnell C, O'Reilly T, Wyder L, et al. (2006) Antagonism of sphingosine-1-phosphate receptors by FTY720 inhibits angiogenesis and tumor vascularization. Cancer Res 66: 221-231.

44. Schmid G, Guba M, Ischenko I, Papyan A, Joka M, et al. (2007) The immunosuppressant FTY720 inhibits tumor angiogenesis via the sphingosine 1-phosphate receptor 1. J Cell Biochem 101: 259-270.

45. Li CX, Shao Y, Ng KT, Liu XB, Ling CC, et al. (2012) FTY720 suppresses liver tumor metastasis by reducing the population of circulating endothelia progenitor cells. PLoS One 7: e32380.

46. Huang D (2015) Disseminated cryptococcosis in a patient with multiple sclerosis treated with fingolimod. Neurology 85: 1001-1003.

47. Achtnichts L, Obreja O, Conen A, Fux CA, Nedeltchev K (2015) Cryptococcal Meningoencephalitis in a Patient With Multiple Sclerosis Treated With Fingolimod. JAMA Neurol 72: 1203-1205.

48. Simula S, Laitinen T, Laitinen TM, Tarkiainen T, Hartikainen P, et al. (2015) Effect of fingolimod on cardiac autonomic regulation in patients with multiple sclerosis. Mult Scler.

49. Russo M, Guarneri C, Mazzon E, Sessa E, Bramanti P, et al. (2015) Fingolimod Associated Peripheral Vascular Adverse Effects. Mayo Clin Proc 90: 14241427.

50. Cohan S, Godwin J, Gaedeke L (2015) Acute Lymphoblastic Leukemia in a Man Treated With Fingolimod for Relapsing Multiple Sclerosis. J Investig Med High Impact Case Rep 3: 2324709615575551.

51. Schroder K, Finis D, Harmel J, Ringelstein M, Hartung HP, et al. (2015) Acetazolamide therapy in a case of fingolimod-associated macular edema: early benefits and long-term limitations. Mult Scler Relat Disord 4: 406-408.

52. Kraemer M, Weber R, Herold M, Berlit P (2015) Reversible cerebral vasoconstriction syndrome associated with fingolimod treatment in relapsingremitting multiple sclerosis three months after childbirth. Mult Scler 21: 14731475

53. Samaraweera AP, Cohen SN, Akay EM, Evangelou N (2016) Lymphomatoid papulosis: A cutaneous lymphoproliferative disorder in a patient on fingolimod for multiple sclerosis. Mult Scler 22: 122-124.

54. Conzett KB, Kolm I, Jelcic I, Kamarachev J, Dummer R, et al. (2011) Melanoma occurring during treatment with fingolimod for multiple sclerosis: a case report Arch Dermatol 147: 991-992.

\section{OMICS International: Publication Benefits \& Features}

\section{Unique features:}

- Increased global visibility of articles through worldwide distribution and indexing

- Showcasing recent research output in a timely and updated manner

Special issues on the current trends of scientific research

Special features:

$700+$ Open Access Journa

$50,000+$ editorial team

Rapid review proces

Quality and quick editorial, review and publication processing

Indexing at major indexing services

Sharing Option: Social Networking Enabled

Authors, Reviewers and Editors rewarded with online Scientific Credits

Befter discount for your subsequent articles

Submit your manuscript at: http://www.omicsonline.org/submission 